Article

\title{
Impacts of Rural Labor Resource Change on the Technical Efficiency of Crop Production in China
}

\author{
Ning Yin and Yapeng Wang * \\ College of Economics \& Management, Huazhong Agricultural University, Wuhan 430070, China; \\ ningyin2016@foxmail.com \\ * Correspondence: wangyp@mail.hzau.edu.cn; Tel.: +86-135-9555-6336 \\ Academic Editor: Les Copeland \\ Received: 25 December 2016; Accepted: 9 March 2017; Published: 11 March 2017
}

\begin{abstract}
This paper probes effects of the evolvement of labor resources on technical efficiency in crop production in rural China. Based on twelve years of data on crop production of 30 provinces in China, a stochastic frontier production function model is used to measure crop production efficiency in three crop-functional areas-the production area, the consumption area, and the balanced area. Then effects of both quantity and quality change in labor force on technical efficiency in different regions of China are analyzed. Results show that rural China generally has an increasing number of employees shifted to non-agricultural sectors and a decreasing trend of the stock of human capital. However, both these two changes in rural labor force have significantly positive effects on improving crop production efficiency. In addition, China's technical inefficiency is at an average of $22.2 \%$. Dynamically, the technical efficiencies show a tendency to rise steadily throughout China and in three areas, while the consumption area possesses the highest technical efficiency. Those results may lend some experience for other countries that are currently experiencing rural labor force and economic transition.
\end{abstract}

Keywords: labor; rural migration; human capital; technical efficiency; crop production

\section{Introduction}

Economic growth of traditional agriculture depends largely on the initial endowments mainly including labor and land input, whereas the engine for modern agricultural growth has been proved to be factors such as capital input and well-qualified labor input [1,2]. The concept, human capital, has been employed to reveal the source of technical progress, which makes increasing contribution to output growth in modern agriculture. China has witnessed steady growth in crop production over the past ten years. Both accumulated productive factor inputs and advancing technical efficiency in crop production are contributors to this encouraging growth. Nevertheless, technical efficiency as a main embodiment of production efficiency makes more sustainable contribution to output growth than productive factors [3].

Several studies have focused on the analysis of technical efficiency, especially on its measurement and influential factors. Existing methods of measuring technical efficiency include stochastic frontier analysis (SFA) and data envelopment analysis (DEA) [4,5]; factors influencing technical efficiency cover human capital, family characteristics, agricultural public investment, transport infrastructure, and other social elements [6,7]. Among these factors, human capital shows a significantly positive impact on technical efficiency in many fields $[8,9]$ and plays an important role in explaining regional differences of technical efficiency [10]. For the purpose of ensuring the long-term sustainable development of the Chinese economy, increasing the investment of human capital and improving the efficiency of technology application and crop production are of particular importance. 
With the deepening industrialization and urbanization in China, traditional factors start to fail to satisfy the demands of modern agriculture development, so requirements for the conformation of new factor inputs have been put forward. Meanwhile, due to technical progress, rural labor resources have been experiencing changes in both quantity and quality. Many researchers contend that human capital has an increasingly pronounced effect in the development of society, economy, employment, income, and so on [11-14]. Specifically, the evolvement of rural labor resources, especially rural migration, has an increasingly important influence on grain output and economic development in the countryside [15-17]. However, questions still remain to be discussed on the impacts of both quantity and quality change in labor resources in rural China on crop production efficiency, differences among sub-national areas of China, and the trend of China's crop production efficiency under this circumstance.

The objective of this study is to explore the relationship between the change in rural labor resources and crop production efficiency in China. The important part of this study is the consideration of the heterogeneity of rural laborers. The crop production efficiency is analyzed from both perspectives of the quantity and quality change in rural labor resources. Since rural labor resources denote physical as well as mental power in rural areas, in this study, the evolvement of rural labor resources is defined as the dual-effects of the decreasing population caused by rural migration and the quality improvement due to accumulated human capital stock. It is hoped that this study may lend some support for agricultural policy-making for countries also experiencing extensive rural migration and changes in the labor force. Additionally, most existing research starts on a macroeconomic, national level, while few have obtained a regional perspective. Among the few studies from a sub-national perspective, three areas-Eastern, Middle, and Western China are mostly explored, but this dividing standard overlooks the characteristics of targeted crop production. Therefore, in this study, the regions studied are divided according to resource endowments, comparative advantages, and consumption characteristics of each area for crop production, according to the dividing standard put forward in government documents.

\section{Empirical Specification}

In this research, the following function will be applied to estimate technical efficiency according to the stochastic frontier production function model affected by technical inefficiency [18-20]:

$$
Y_{i t}=f\left(X_{i t}, \beta\right) \exp \left(v_{i t}-u_{i t}\right) \quad(i=1, \ldots, N)
$$

Then, the model can be turned into the following form by taking the logarithm:

$$
\ln Y_{i t}=\ln f\left(X_{i t}, \beta\right)+v_{i t}-u_{i t}
$$

where $Y_{i t}$ represents the grain output of province $i$ in $t$ period; $X_{i t}$ denotes the total factor input of province $i$ in $t$ period; $\beta$ is an unknown parametric vector; $f\left(X_{i t}, \beta\right)$ is the production frontier which shows the optimal production technology, with the definition "the maximum possible output gained within given factor inputs and their combinations." The error term $\left(v_{i t}-u_{i t}\right)$ falls into two parts. $v_{i t} \sim N\left(0, \sigma^{2}{ }_{v}\right)$ is a systematic random error representing the uncontrollable factors such as disasters and measurement errors; $u_{i t}$ denotes the inefficiency which affects output, namely, the distance between real production and the frontier. $u_{i t}$ is subjected to the condition $u_{i t} \geq 0$ and $u_{i t} \sim N\left(M_{i t}, \delta, \sigma^{2}{ }_{u}\right)$, among which $M_{i}$ is an exogenous variable related to efficiency.

The crop production efficiency is measured by the ratio of observed outputs to the corresponding stochastic outputs. This measuring method is the most frequently used output-oriented technical efficiency in previous studies [18]. The technical efficiency (TE) of crop production can be expressed as follows:

$$
\mathrm{TE}_{i}=\frac{E\left[f\left(X_{i t}, \beta\right) \exp \left(v_{i t}-u_{i t}\right)\right]}{E\left[f\left(X_{i t}, \beta\right) \exp \left(v_{i t}-u_{i t}\right) \mid u_{i t}=0\right]}=\exp \left(-u_{i t}\right) .
$$


This ratio is in a $[0,1]$ interval due to the non-negativity of $u_{i t}$, which means TE $=1$ when there is no efficiency loss $\left(u_{i t}=0\right)$. The model is estimated with a maximum likelihood method instead of an ordinary least squares (OLS) method because the error term in the stochastic frontier production function fails to be subject to classical assumptions in OLS. In addition, we make a distributional hypothesis to the two error terms: making $\sigma^{2}{ }_{v}$ and $\sigma^{2}{ }_{u}$ substituted by $\lambda=\sigma^{2}{ }_{u} /\left(\sigma^{2}{ }_{v}+\sigma^{2}{ }_{u}\right)$, among which $\lambda$ belongs to a $[0,1]$ interval. In this way, the significance of inefficiency can be shown clearly when we estimate $\lambda$. When $\lambda$ is close to 1 , the error is mainly caused by inefficiency in technology use. On the contrary, $\lambda$ being close to 0 means that random error is the primary reason for the error in the frontier production function.

Battese and Coelli [21] proposed the technical inefficiency model as an extension model for inefficiency effects in stochastic frontiers for the cross-sectional data. The inefficiency term $u_{i t}$ is defined as follows:

$$
u_{i t}=M_{i t} \delta+\omega_{i t}
$$

where $M_{i t}$ denotes the exogenous variables affecting inefficiency; $\delta$ is the parameter to be estimated; random variable $\omega_{i t}$ is subject to a normal distribution $u_{i t} \sim N\left(u_{i t}, \sigma^{2}{ }_{u}\right)$, which is truncated at $-\mathrm{M}_{i t} \delta$.

Based on the above discussion on model choosing, a stochastic frontier production function model is adopted in this paper to measure the technical efficiency in China's crop production. A function of technical inefficiency is also employed to analyze the implication of migration in different crop production areas on its technical efficiency. When it comes to production function choosing, several functions such as Leontief function, quadratic function, Cobb-Douglas production function, and so on can be applied [22]. Cobb-Douglas production function, a common and standard model in previous production researches, is employed in this study.

According to the literature and available dataset, the input variables included in the production frontier model are the classic production inputs: land, labor, and capital. Land denotes the total cultivated area, while Labor refers to the total labor used for crop production. Capital input is captured by two main factors, mechanical traction input and fertilizer use. These variables have different statistical standards, so we adjusted and converted these variables to maintain consistency with the statistical criteria of crop production. The modification is based on the following methods:

(a) Labor inputs in crop production $=$ employment in primary industry $\times$ (agricultural outputs $/$ primary industry outputs) $\times$ (cultivated area of food/cultivated area of agricultural products);

(b) The ratio "cultivated area of food/cultivated area of agricultural products" is used to modify and compute machine use, fertilizer, and pesticide use.

Therefore, referring to Equation (2), the function is specified as follows:

$$
\ln Y_{i t}=\beta_{0}+\beta_{1} \ln X_{1 i t}+\beta_{2} \ln X_{2 i t}+\beta_{3} \ln X_{3 i t}+\beta_{4} \ln X_{4 i t}+v_{i t}-u_{i t}
$$

where $Y_{i t}$ depicts the total grain output of province $i$ in $t$ period, the sum of rice, wheat and corn outputs; $X_{m i t}(m=1, \ldots, 4)$ represents four types of factor inputs of province $i$ during $t$ period, including labor input, cultivated area, mechanical traction input, and fertilizer input in crop production. $\beta_{m}(m=1, \ldots, 4)$ is the coefficient representing the output elasticity of labor input, cultivated area, mechanical traction input, and fertilizer input, respectively, and $u_{i t}$ represents effects of technical inefficiency.

Despite the lack of accurate statistics on migration in China's official database, quite a few methods measuring migration volume have been applied in previous studies. One refers to the calculating method: the amount of migration $=$ (urban employment - urban registered staffs $)+($ total rural employment - rural agricultural employment) [23]; while another method uses the difference between actual employees between agriculture and primary industry to show the amount of migration [24]. In this study, a new index to show migration scale, the ratio of employees in agriculture to employees in all industries, is adopted for two reasons. Firstly, the annual change of this index exactly reflects the 
rural-to-urban migration trend-the decline of this ratio indicates an increasing amount of migration. Secondly, the purpose of this study is to grasp the implication of migration on crop production efficiency from a macroeconomic perspective, so this new index appears more clear and direct.

The stock of human capital is also a very important variable apart from the migration variable. According to Schults' theory of human capital [25], among all factor inputs, human capital is the primary resource in economic growth. The process of rural-to-urban migration can be seen as farmers' decision-making process that helps them find an optimal price for human capital. An expanding body of literature has proven that the overall quality of farmers is dynamically improved due to the popular value on human capital investment, though the loss of rural human capital occurs during labor outflow [26-28]. To our knowledge, few studies, however, have probed the relationship between human capital and crop production efficiency with an empirical method. Admitting the basic fact of rural laborers' heterogeneity, this study integrates human capital as a variable into the migration index to reflect the influence of rural human capital change on crop production efficiency. The level of human capital is represented by a variable $H_{i}$, which shows the scalable stock of human capital [29]. The computing function is $H_{i}=e^{\phi(E i) R} L_{i}=h_{i} L$, where $\phi\left(E_{i}\right)$, under the condition $\phi(0)=0$, is the production efficiency of laborers who have had education for $E$ years. Different from previous studies that use years of education to measure the quality of labor force, this method highlights that different education stages contributing differently to production efficiency. The education attainment of rural laborers in each province is calculated annually, referring to the method of counting education span and return rate in a study by $\mathrm{Li}$ [30]. The variable $L_{i}$ represents the human capital of an ordinary laborer, so the volume of agricultural employees is used.

Therefore, referring to Equation (4), migration and the stock of human capital considered, the inefficiency model in this study is as follows:

$$
u_{i t}=\delta_{0}+\delta_{1} M_{1 i t}+\delta_{2} M_{2 i t}+\omega_{i t}
$$

where explanatory variable $M_{1}$ is the ratio of agricultural employees to employees in all industries, representing the migration scale; $M_{2}$ captures the stock of human capital; $i$ presents the cross-section unit of dataset; $t$ reflects the 12 years of time series from 2001 to 2012. Parameters $\delta_{1}$ and $\delta_{2}$ represent the influence of labor outflow (proportion of non-agricultural industries) and rural human capital on crop production inefficiency, respectively. A positive numerical value of $\delta$ means a positive influence on inefficiency, namely a negative impact on technical efficiency and otherwise.

\section{Material and Methods}

In this study, we use a panel dataset of 30 provinces in China from 2001 to 2012, excluding 4 provinces (Hong Kong, Macao, Taiwan, and Tibet) because these areas possess particular resource endowment and productivity. The panel data are drawn from China Rural Statistical Yearbook and China Statistical Yearbook published by the National Bureau of Statistics (NBS) [31,32]. Since these yearbooks cover data from previous years, we used yearbooks from 2002-2013. Unfortunately, data on our key variable, rural employee volume in the primary industry in 2013, have not yet been included. The most updated data we were able to use was that from 2012. This may be one of the shortcomings of this study, and more information is needed for further research.

To capture a better understanding of disparities in different regions in China, we divided these 30 provinces into three crop-functional areas: the production area, the consumption area, and the balanced area (Table 1), according to the dividing standard put forward in government documents considering regional resource endowment, comparative advantages, and consumption characteristics. In the crop production area, the total volume of crop production is larger than the total volume of crop that has been consumed. On the contrary, in the consumption area, the amount of crop consumed is larger than that of produced crop. Compared to the balanced area, the two volumes are basically equal. 
Compared with studies dividing China into eastern, middle, and western areas [33,34], this regionalism appears more targeted when crop production is the focus of research.

The descriptive statistics of variables (Table 2) reveal some interesting patterns. For instance, the production area has an absolute advantage in factor input volume; however, when labor resources are focused on, we find that the migration scale in the production area and the balanced area are roughly close, while the stock of human capital varies in each area. The stock of human capital in the production area is approximately twice the stock volume in the balanced area. This suggests an evolvement disparity of human capital in these two different areas. The larger stock of human capital in the production area may derive from two aspects: the preliminary large quantity of labor force and the improvement of education attainment in this area.

The consumption area experiences the lowest rate of agricultural employees, which is reasonable because, in the consumption area, the first industry does not dominate in economic development. Therefore, redundant rural laborers have more initiations and opportunities to participate in off-farm employment. Theories on migration motivation have demonstrated that the economic development gap has been an important contributor to migration [35-37].

Table 1. Provinces that are included in three crop-functional areas.

\begin{tabular}{|c|c|}
\hline Crop Functional Area & Provinces \\
\hline production area & $\begin{array}{l}\text { Liaoning, Hei Longjiang, Jilin, Hebei, Inner Mongolia, Shandong, Jiangsu, } \\
\text { Anhui, Jiangxi, Henan, Hubei, Hunan and Sichuan }\end{array}$ \\
\hline consumption area & Beijing, Tianjin, Shanghai, Zhejiang, Fujian, Guangdong and Hainan \\
\hline balanced area & $\begin{array}{l}\text { Shanxi, Chongqing, Guangxi, Ningxia, Xinjiang, Qinghai, Shaanxi, Yunnan, } \\
\text { Guizhou and Gansu }\end{array}$ \\
\hline
\end{tabular}

Table 2. Descriptive statistics of output and inputs in three crop-functional areas.

\begin{tabular}{|c|c|c|c|c|c|c|c|c|}
\hline & & $\begin{array}{c}\text { Total Grain } \\
\text { Output } \\
\left(10^{4} \text { tons }\right)\end{array}$ & $\begin{array}{l}\text { Labor Input } \\
\left(10^{4} \text { person }\right)\end{array}$ & $\begin{array}{c}\text { Cultivated } \\
\text { Area } \\
\left(10^{3} \text { hectare }\right)\end{array}$ & $\begin{array}{c}\text { Mechanical } \\
\text { Traction } \\
\left(\mathbf{1 0}^{4} \mathbf{k w}\right)\end{array}$ & $\begin{array}{l}\text { Fertilizer } \\
\text { Use } \\
\left(10^{4} \text { tons }\right)\end{array}$ & $\begin{array}{c}\text { Employee } \\
\text { Proportion } \\
(\%)\end{array}$ & $\begin{array}{c}\text { Stock of } \\
\text { Human Capital } \\
\left(10^{4} \text { persons }\right)\end{array}$ \\
\hline \multirow{3}{*}{$\mathbf{N}$} & S.D. & 1303.62 & 266.69 & 2604.85 & 1732.70 & 89.96 & 0.16 & 1015.03 \\
\hline & Max & 5761.49 & 1477.72 & $11,519.54$ & 8231.54 & 479.18 & 0.88 & 4748.33 \\
\hline & Min & 58.03 & 8.15 & 141.34 & 39.69 & 2.54 & 0.16 & 50.49 \\
\hline \multirow{3}{*}{ PA } & S.D. & 995.71 & 279.90 & 2097.77 & 1984.18 & 85.87 & 0.11 & 1051.21 \\
\hline & Max & 5761.49 & 1477.72 & $11,519.54$ & 8231.54 & 479.18 & 0.82 & 4748.33 \\
\hline & Min & 1239.10 & 178.08 & 2743.27 & 591.15 & 60.87 & 0.30 & 675.63 \\
\hline \multirow{2}{*}{ CA } & Mean & 490.56 & 119.21 & 934.43 & 529.50 & 41.66 & 0.43 & 664.66 \\
\hline & S.D. & 457.97 & 134.23 & 871.44 & 437.72 & 40.02 & 0.17 & 711.75 \\
\hline \multirow{2}{*}{ BA } & $\operatorname{Max}$ & 1749.10 & 757.90 & 4399.57 & 2641.48 & 176.95 & 0.88 & 2285.21 \\
\hline & Min & 86.80 & 24.33 & 169.43 & 106.27 & 2.54 & 0.43 & 54.40 \\
\hline
\end{tabular}

Note: $\mathrm{N}$ stands for the nationwide data; PA stands for the production area; CA is the consumption area, BA is the balanced area.

\section{Results and Discussions}

\subsection{Migration and the Stock of Human Resource Change}

Table 3 shows the change in the average proportion of employees in the primary industry to employees in all three industries, as well as the trend of average stock of human capital. Since the annual change in employee proportion measures the ratio of employees in the first industry, a decreasing trend, as shown in the results, indicates that people taking jobs in the first industry 
is declining and the amount of laborers taking off-farm employment is increasing. This reflects an increasing migration scale to the non-agricultural sectors.

As the migration is increasing, rural China experiences a descending stock of human capital. Both quantity and quality change in rural labor force have contributed to this decrease. With more rural labor force migrating to non-agricultural sectors, the remaining laborers in rural areas tend to be the elderly, children, and women. Studies have shown that young and more educated laborers are more likely to migrate $[38,39]$. Consequently, problems including rural aging laborers, female farmers, and unattended children have been increasingly prominent in recent China [38,40].

Table 3. The average migration scale and stock of human resource change in China.

\begin{tabular}{ccc}
\hline Year & Employee Proportion & Stock of Human Capital \\
\hline 2001 & 1374.82 & 0.68 \\
2002 & 1359.63 & 0.67 \\
2003 & 1334.16 & 0.65 \\
2004 & 1310.26 & 0.63 \\
2005 & 1303.03 & 0.61 \\
2006 & 1287.62 & 0.59 \\
2007 & 1263.32 & 0.57 \\
2008 & 1259.72 & 0.56 \\
2009 & 1256.72 & 0.55 \\
2010 & 1247.14 & 0.54 \\
2011 & 1219.13 & 0.53 \\
2012 & 1211.66 & 0.52 \\
\hline
\end{tabular}

\subsection{Crop Production Efficiency}

The crop production efficiency in China and the three crop-functional areas from 2001 to 2012 is measured respectively with Equation (3). Results show that the average technical efficiency displays a marked difference in the three areas (Table 4). The highest technical efficiency goes to the main consumption area and then the production area. A possible explanation for this result may be that the economic power of the consumption area ensures its advantage in agricultural technology application, which is exactly what the technical efficiency represents. In all of China, technical inefficiency is at an average of $22.2 \%$, possibly deriving from two facts. Firstly, the technical frontier is gradually advanced because of the rapid technical progress, so the measuring standard of technical efficiency is pushed forward constantly; secondly, technical efficiency loss occurs when heterogeneous farmers fail to fully utilize new technology because they are confined to household conditions and endowments.

Table 4. The crop production efficiency in China and three crop-functional areas.

\begin{tabular}{ccccc}
\hline Year & Nationwide & Production Area & Consumption Area & Balanced Area \\
\hline 2001 & 0.752 & 0.764 & 0.860 & 0.717 \\
2002 & 0.765 & 0.783 & 0.859 & 0.734 \\
2003 & 0.750 & 0.738 & 0.853 & 0.739 \\
2004 & 0.774 & 0.786 & 0.873 & 0.750 \\
2005 & 0.767 & 0.790 & 0.874 & 0.748 \\
2006 & 0.780 & 0.810 & 0.903 & 0.731 \\
2007 & 0.779 & 0.792 & 0.908 & 0.747 \\
2008 & 0.791 & 0.826 & 0.916 & 0.754 \\
2009 & 0.779 & 0.805 & 0.914 & 0.756 \\
2010 & 0.786 & 0.827 & 0.910 & 0.762 \\
2011 & 0.799 & 0.861 & 0.923 & 0.756 \\
2012 & 0.814 & 0.875 & 0.922 & 0.791 \\
Average & 0.778 & 0.805 & 0.893 & 0.749 \\
\hline
\end{tabular}


Seen from a dynamic perspective, the technical efficiency in China and three functional areas is ascending constantly except for the general slump in 2003. In 2003, the main production area and the main consumption area witnessed the lowest technical efficiency: 0.738 and 0.853 , respectively. This is in relation to three years of grain output reduction from 2000 to 2002 when farmers' grain planting initiatives diminished. Because of the low prices, the enthusiasm of farmers to produce grain crops tended to descend. At the same time, the arable land in China had declined in these three years, which also contributed to the reduction of grain output. However, the subsidies on crop production and agricultural tax exemption policy were published in 2004 to encourage farmers to grow grain products, and prove to be effective. The technical efficiency of the whole China, the main production area and the main consumption area increased by $2.4 \%, 5.2 \%$, and 2.0\%, respectively, from 2003 to 2004 .

\subsection{Output Elasticity of Input Factors}

Equations (5) and (6) are estimated with the method of three-stage maximum likelihood estimation. Firstly, the output elasticity and other parameters are estimated with the OLS method. We then attain the variance ratio through a two-phase grid search and use this ratio to adjust output elasticity and other parameters. At last, the maximum likelihood estimated value is obtained with numerical method using these parameters as initial values [21]. The estimation result (Table 5) shows that all coefficients are highly significant at a $1 \%$ or $5 \%$ level, except for the coefficient for mechanical traction in the production and consumption areas and that for labor input in the main consumption area.

Table 5. Estimation results of stochastic frontier production function model.

\begin{tabular}{ccccc}
\hline & Variable & Parameter & Coefficient & Std. Err. \\
\hline & constant & $\beta_{0}$ & -0.086 & 0.124 \\
Nationwide Scope & labor & $\beta_{1}$ & $-0.175^{* * *}$ & 0.025 \\
& land & $\beta_{2}$ & $0.957^{* * *}$ & 0.031 \\
& machine & $\beta_{3}$ & $0.046^{* *}$ & 0.018 \\
& fertilizer & $\beta_{4}$ & $0.127^{* * *}$ & 0.028 \\
\hline & constant & $\beta_{0}$ & 2.548 & 0.002 \\
Production Area & labor & $\beta_{1}$ & $-0.121^{* * *}$ & 0.013 \\
& land & $\beta_{2}$ & $0.571^{* * *}$ & 0.011 \\
& machine & $\beta_{3}$ & 0.002 & 0.017 \\
& fertilizer & $\beta_{4}$ & $0.279^{* * *}$ & 0.024 \\
\hline \multirow{5}{*}{ Consumption Area } & constant & $\beta_{0}$ & -0.503 & 1.288 \\
& labor & $\beta_{1}$ & 0.015 & 0.082 \\
& land & $\beta_{2}$ & $1.083^{* * *}$ & 0.333 \\
& machine & $\beta_{3}$ & -0.008 & 0.168 \\
& fertilizer & $\beta_{4}$ & $-0.176^{* * *}$ & 0.044 \\
\hline \multirow{3}{*}{ Balanced Area } & constant & $\beta_{0}$ & $2.725^{* * *}$ & $3.40 \times 10^{-8}$ \\
& labor & $\beta_{1}$ & $-0.213^{* * *}$ & $7.76 \times 10^{-9}$ \\
& land & $\beta_{2}$ & $0.617^{* * *}$ & $1.11 \times 10^{-8}$ \\
& machine & $\beta_{3}$ & $-0.049^{* * *}$ & $3.76 \times 10^{-9}$ \\
& fertilizer & $\beta_{4}$ & $0.261^{* * *}$ & $3.24 \times 10^{-9}$ \\
\hline
\end{tabular}

Notes: ${ }^{* *}$ and ${ }^{* * *}$ indicate estimated coefficients are statistically significant at $5 \%$ and $1 \%$, respectively.

Output elasticity of labor input in crop production is negative from the nationwide perspective, which means that there is surplus labor in China's crop production. This is accordant with results of previous studies [6]. When regional results are considered, only the consumption area has a positive, but not significant, output elasticity of labor input, while the production area and the balanced area have negative ones. This robust result implies that there is surplus labor in rural China, and increasing the quantity of labor input in crop production alone cannot necessarily lead to output growth, but studies have suggested a positive effect of ameliorating the quality of labor resources on yields growth [34]. 
Output elasticity of cultivated area appears to be positive and significant at a $1 \%$ level in four models. The robust result means that enlarging cultivated areas of crops can improve grain output, which conforms to the neoclassic economic theory. Although the model agricultural production increasingly depends less on the enlargement of land resource because of the scarcity, ensuring the fundamental levels of farming land is necessary when taking food security into consideration.

Capital inputs have shown significantly positive impacts on grain output growth nationwide, which implies that more investments on mechanization and fertilizer can contribute to crop production improvement. This result strongly supports opinions of neoclassic economics that a capital factor plays an important role in production function formation. It is also clear that China's agricultural development at the present stage can still be identified as neoclassic agricultural development. This developing pattern is an accompanying process with China's industrialization and reflects the positive impact of industrialization on agricultural development.

Among the capital inputs, fertilizer input is significantly positive in the production and balanced areas, while a significantly negative coefficient is shown in the consumption area. This supports the findings of previous studies that proper chemical input can contribute to crop production, but excessive use of fertilizer does occur [41]. Additionally, with the development of agricultural mechanization, the parameter of mechanical traction in crop production is negative, except for the production area where the mechanization level still needs to be improved.

Results from perspectives of different functional areas suggest that different aims should be directed at improving crop production in different areas. To achieve more efficient and targeted policies, investment in capital input should have a distinct emphasis on different crop-functional areas.

\subsection{Technical Inefficiency}

The estimation results of Equation (6) show the technical inefficiency nationwide and in three functional areas (Table 6). The estimation results of $\lambda$ are significant and close to 1 , which indicates that technical inefficiency consequently leads to most errors when input factors are under control.

The estimation results of $\delta_{1}$ (Table 6) show that the migration scale in a region has a pronounced impact on crop production efficiency. Notably, the interpretation of signs of coefficients needs to be clarified. As regards the coefficient of $\delta_{1}$ in the nationwide model, since migration scale is interpreted by the ratio of employees in the agricultural sector to employees in all industries, a larger ratio means more people stay in the agricultural sector and indicates a lower migration degree. The positive parameter of the migration scale indicates that, when more people are employed in the agricultural sector, i.e., the migration scale is smaller, there is more technical inefficiency. To make it simple, when employees in the agricultural sector comprise a larger proportion, crop production is less affected. Therefore, after laborers migrate from agricultural sectors, this proportion decreases, and crop production efficiency increases. The estimation results of $\delta_{1}$ show that rural migration helps to improve crop production efficiency in rural China, as well as in the production and balanced areas. For all of China, a $1 \%$ drop in employment in the agricultural sector corresponds to a $0.6 \%$ rise in technical efficiency. In the consumption area where the migration level is higher, labor needs to increase in the agricultural sector.

The estimation results of $\delta_{2}$ show that the stock of rural human capital poses a significant impact on technical inefficiency of crop production. The negative values of $\delta_{2}$, all of which are significant at the $99 \%$ level, indicate a positive traction of human capital to technical efficiency. The balanced area, compared to the other two areas, experiences improved effects of the stock of rural human capital on the improvement of technical efficiency. However, the positive effects of human capital are limited because no $\delta_{2}$ coefficients, nationwide or in the three areas, are larger than 0.02 . This does not necessarily mean that the stock of human capital is not important for technical efficiency improvement. One reason could be that the stock of human capital is decreasing annually, and the positive effects can hardly contribute to the increase in technical efficiency. 
Generally, the evolvement of rural labor resources in China has a positively significant impact on crop production efficiency in China. Government efforts on the improvement of crop production efficiency in China should increase efforts to achieve the quality amelioration of rural laborers and the advancement of rural migration. On the other hand, the regional disparity of the impact shows that reinforcing education and migration plays a more essential role in the balanced area for the purpose of improving technical efficiency of crop production.

Table 6. Estimates of technical inefficiency model.

\begin{tabular}{|c|c|c|c|c|}
\hline & Variables & Parameter & Coefficient & Std. Err. \\
\hline \multirow{5}{*}{ Nationwide Scope } & constant & $\delta_{0}$ & 0.005 & 0.107 \\
\hline & migration scale & $\delta_{1}$ & $0.605^{* * *}$ & 0.132 \\
\hline & the stock of rural human capital & $\delta_{2}$ & $-0.0001^{* * *}$ & 0.00003 \\
\hline & & $\lambda$ & $0.953^{* * *}$ & 0.020 \\
\hline & \multicolumn{2}{|c|}{ logarithm of likelihood function } & 156.136 & \\
\hline \multirow{5}{*}{ Production Area } & constant & $\delta_{0}$ & $0.256^{* * *}$ & 0.065 \\
\hline & migration scale & $\delta_{1}$ & $0.247^{* *}$ & 0.104 \\
\hline & the stock of human capital & $\delta_{2}$ & $-0.0001^{* * *}$ & 0.00002 \\
\hline & & $\lambda$ & $0.994^{* * *}$ & 0.016 \\
\hline & \multicolumn{2}{|c|}{ logarithm of likelihood function } & 123.647 & \\
\hline \multirow{5}{*}{ Consumption Area } & constant & $\delta_{0}$ & -0.060 & 0.549 \\
\hline & migration scale & $\delta_{1}$ & 1.167 & 0.0001 \\
\hline & the stock of human capital & $\delta_{2}$ & -0.002 & 0.001 \\
\hline & & $\lambda$ & $0.644^{* * *}$ & 0.233 \\
\hline & \multicolumn{2}{|c|}{ logarithm of likelihood function } & 94.359 & \\
\hline \multirow{5}{*}{ Balanced Area } & constant & $\delta_{0}$ & $1.347^{* * *}$ & 0.199 \\
\hline & migration scale & $\delta_{1}$ & $-0.697^{* *}$ & 0.277 \\
\hline & the stock of human capital & $\delta_{2}$ & $-0.001^{* * *}$ & 0.0001 \\
\hline & & $\lambda$ & $0.999^{* * *}$ & 0.019 \\
\hline & \multicolumn{2}{|c|}{ logarithm of likelihood function } & 100.132 & \\
\hline
\end{tabular}

Notes: ${ }^{* *}$ and ${ }^{* * *}$ indicate estimated coefficients are statistically significant at $5 \%$ and $1 \%$, respectively. Migration scale is defined as the proportion of employees in the agricultural sector to that in all industries.

\section{Conclusions}

The extensive off-farm migration is a transforming process of resource allocation with a traditional agricultural pattern, since the number of rural laborers descends during this process. Meanwhile, the off-farm migration displays its incentive effect on the demand growth for rural education and investments on human capital. Therefore, the migration has posed an impact on both quantity and quality of agricultural labor. It is under this background that this study focuses on impacts of human capital change on crop production efficiency.

It is found that there exists an increasing migration scale to the non-agricultural sectors and decreasing trend of the stock of human capital in rural China. Additionally, China's technical inefficiency is at an average of $22.2 \%$, and the average technical efficiency displays a marked difference in the three areas. The highest technical efficiency goes to the consumption area and then the production area. Dynamically, the technical efficiencies show a tendency to rise steadily throughout China and in the three crop-functional areas.

One of the major findings is that the decrease in employees in the primary industry is beneficial for improving crop production efficiency. It is not assumed that the migration will make labor a "bottleneck" resource for crop production; on the contrary, redundant labor in production is released by migration, and the resource allocation efficiency can be thus improved. In addition, the off-farm migration can contribute to the scale expanse and specialization of production because the patterns and organizations of crop production are reconstructed during migration. Additionally, off-farm 
employment helps to increase family income and this can help to improve the potential application of new agricultural technology.

The quality of rural labor and the stock of human capital has revealed positively significant but faint effects on technical efficiency improvement. The low marginal effect of labor quality derives from the qualitative surplus of the labor force in rural China. It also reveals that the technical progress in China's agricultural production hardly depends on skill-based technical progress. However, human capital is of paramount importance in agricultural growth.

Agriculture in China is experiencing a transformation from a traditional to modern pattern. During this period, human capital appears to be a crucial explanation for the growth of agricultural outputs because the increase in human capital stock brings higher technical efficiency. This conclusion accords with the New Economic Growth Theory and indicates that the agricultural pattern in China is transforming towards endogenous development. Although this developing pattern mostly exists in developed economies, it will be the orientation and destination of future agriculture in China. Additionally, this can lend experience to other countries that are currently experiencing rural labor force and economic transitions.

Future research on this topic is needed. First, more efforts on the stock of human capital are necessary since it has played an important role in the growth of agricultural economics. Second, obtaining more specific data on the grain production and rural human capital over a longer time period is necessary. Third, future research that focuses on the impact of labor change in the agricultural sector on crop production can unfold from the perspectives of farm households and provide more empirical evidence in other areas in the world.

Acknowledgments: This article is funded by the National Social Science Foundation of China (13AGL004).

Author Contributions: Ning Yin designed the research topic, completed data analysis, and drafted the manuscript; Yapeng Wang provided suggestions to construct and edit the paper.

Conflicts of Interest: The authors declare no conflict of interest.

\section{References}

1. $\mathrm{Xu}, \mathrm{X}$; J Jeffrey, S.R. Efficiency and technical progress in traditional and modern agriculture: Evidence from rice production in China. Agric. Econ. 1998, 3, 157-165. [CrossRef]

2. Yang, M.; Bai, R.; Liu, M. Development of Agricultural Mechanization and Construction of Modern Agriculture. Trans. Chin. Soc. Agric. Mach. 2005, 36, 68-72.

3. Huang, J.; Zhou, X. Technical Efficiency and Growth of Total Factor Productivity of Crop production in China, 1978-2008. South China J. Econ. 2010, 9, 40-52.

4. Liu, N. Evaluation on the Grain Production Capacity of Major Grain Production Area Based on Super-efficiency Output-DEA Model. Soft Sci. 2011, 25, 79-83.

5. Li, G.; Feng, Z.; Fan, L. An Empirical Analysis about the Effect of Household Endowments on the Technical Efficiency of Farmer's Household Management-Evidence from the Farmers of Hubei Province. Stat. Res. 2008, 25, 35-42.

6. Wang, X.; Jiang, T. Research on China Agricultural Technical Efficiency based on Public Investment on Agricultural. Chin. Rural Econ. 2009, 5, 79-86.

7. Li, Z.; Li, D. Empirical Research on the Effect of Transportation Infrastructure Construction on Agricultural Technical Efficiency. Forum Sci. Technol. China 2012, 2, 127-133.

8. Yan, M.; Wang, W. Empirical Test on Technical Efficiency of Human Capital Structure in China Based on Stochastic Frontie. J. Math. Pract. Theory 2012, 42, 11-18.

9. Fu, X.; Wu, L. Technical Efficiency, Capital Deepening and Regional Disparity. Econ. Res. J. 2006, 10, 52-61.

10. Fu, Q.; Jin, N. Empirical Test on Efficiency of Human Capital and R \& D Investment in China Based on Stochastic Frontier Production Function. Tech. Econ. 2009, 28, 5-10.

11. Plummer, P.; Taylor, M. Entrepreneurship and human capital, distilling models of local economic growth to inform policy. J. Small Bus. Enterp. Dev. 2004, 11, 427-439. [CrossRef] 
12. Hong, P.Y.; Pandey, S. Human capital as structural vulnerability of US poverty. Equal Oppor. Int. 2007, 26, 18-43. [CrossRef]

13. Khorasgani, M.F. Higher education development and economic growth in Iran. Educ. Bus. Soc. 2008, 1, 162-174. [CrossRef]

14. Jiang, Y.; Shi, X.; Zhang, S.; Ji, J. The threshold effect of high-level human capital investment on China's urban-rural income gap. China Agric. Econ. Rev. 2011, 3, 297-320. [CrossRef]

15. Fan, D.; Zhu, Y. The Outflow of Agricultural Labor Force on Grain Production Affection in the Context of the Dual Economy. J. Hebei Univ. Econ. Bus. 2012, 33, 39-43.

16. Zhang, X.; Shen, L. The Outflow of Agricultural Labor Force and Economic Development. J. Guangdong Coll. Financ. Econ. 2009, 8, 80-84.

17. $\mathrm{Xu}, \mathrm{C}$. Influence the Outflow of Agricultural Labor Force on Family Supporting. Occup. Circle 2007, 2, 74-76.

18. Xu, H.; Ayachit, M.; Reddyreddy, A. Formal Modeling and Analysis of XML Firewall for Service-Oriented Systems. Int. J. Secur. Netw. 2008, 3, 147-160. [CrossRef]

19. Aigner, D.J.; Lovell, C.A.K.; Schmidt, P. Formulation and estimation of stochastic frontier production function models. J. Econom. 1977, 6, 21-37. [CrossRef]

20. Meeusen, W.; van Den Broeck, J. Estimation from Cobb-Douglas production functions with composed error. Int. Econ. Rev. 1977, 18, 435-444. [CrossRef]

21. Battese, G.E.; Coelli, T.J. A model for technical inefficiency effects in a stochastic frontier production function for panel data. Empir. Econ. 1995, 20, 325-332. [CrossRef]

22. Griffin, R.C.; Montgomery, J.M.; Rister, M.E. Selecting functional form in production function analysis. Western J. Agric. Econ. 1987, 12, 216-227.

23. Guo, J.; Li, Z. Agricultural Output Increase under the Context of Selective Labor Transfer, A Empirical Test of Hypothesis of Non-Skill-Biased Technical Change and Quality-Surplus Labor Force. Jilin Univ. J. Soc. Sci. Ed. 2011, 51, 100-110.

24. He, J.; Shu, H.; Tian, Y. Study on Calculation of Rural Labor Force Transfer in China and Influential Factors. China Popul. Resour. Environ. 2011, 21, 148-152.

25. Schultz, T.W. Investment in human capital. Am. Econ. Rev. 1961, 51,1-17.

26. Li, Z.; Guo, J. Selective Labor Transfer and Human Capital, the Theory and the empirical. Thinking 2010, 36, 112-117.

27. Bai, N.; Li, J. China's Urbanization and Rural Labor Migration. Chin. J. Popul. Sci. 2008, 4, 1-10.

28. Sheng, L. Analysis of the Determinants of Rural Labor Migration in China. China Rural Surv. 2007, 3, 2-15.

29. Hall, R.; Jones, C. Why do Some Countries Produces Much More Output per Worker than Others? Q. J. Econ. 1999, 114, 83-116. [CrossRef]

30. Li, G. Human Capital and TFP Growth of Regional Agriculture in China, Empirical Study Based on Data Envelopment Analysis. J. Financ. Econ. 2009, 35, 115-128.

31. National Bureau of Statistics of China (NBSC). China Rural Statistical Yearbook 2002-2011; NBSC: Beijing, China, 2014.

32. National Bureau of Statistics of China (NBSC). China Statistical Yearbook 2002-2011; NBSC: Beijing, China, 2014.

33. Hu, J.; Wang, S.; Yeh, F. Total-factor water efficiency of regions in China. Resour. Policy 2006, 31, $217-230$. [CrossRef]

34. Ma, J.; Ma, Y.; Bai, Y.; Xia, B. Study on the Technical Efficiency of Creative Human Capital in China by Three-Stage Data Envelopment Analysis Model. Discret. Dyn. Nat. Soc. 2014, 2014, 964275. [CrossRef]

35. Stark, Q. Rural-to-urban migration in less developed countries. Econ. Dev. Cult. Chang. 1984, 32, 475-486. [CrossRef]

36. De Brauw, A.; Rozelle, S.; Taylor, E. Migration remittances and agricultural productivity in China. Am. Econ. Rev. 1999, 89, 287-291.

37. De Brauw, A. Seasonal migration and agricultural production in Vietnam. J. Dev. Stud. 2010, 46, 114-139. [CrossRef]

38. Heenan, D. Social capital and older people in farming communities. J. Aging Stud. 2010, 24, 40-46. [CrossRef]

39. Benjamin, D.; Brandt, L.; Rozelle, S. Aging, wellbeing and social security in rural northern China. Popul. Dev. Rev. 2000, 26, 89-116. 
40. Zhou, Z.; Sun, X.; Liu, Y. Psychological Development and Education Problems of Children Left in Rural Areas. J. Beijing Norm. Univ. 2005, 1, 71-79.

41. Verhoeven, J.; Arheimer, B.; Yin, C.; Hefting, M. Regional and global concerns over wetlands and water quality. Trends Ecol. Evol. 2006, 21, 96-103. [CrossRef] [PubMed] 